\title{
Study on Wellbore Stability and Failure Regions of Shale considering the Anisotropy of Wellbore Seepage
}

\author{
Fan Zhang $\mathbb{D}^{1}{ }^{1}$ Houbin Liu, ${ }^{2}$ Yingfeng Meng, ${ }^{2}$ Shuai Cui, ${ }^{2}$ and Haifeng $\mathrm{Ye}^{3}$ \\ ${ }^{1}$ Shaanxi Key Laboratory of Advanced Stimulation Technology for Oil \& Gas Reservoirs, Xi'an Shiyou University, \\ Xi'an 710065, China \\ ${ }^{2}$ State Key Laboratory of Oil and Gas Reservoir Geology and Exploitation, Southwest Petroleum University, Chengdu 610500, China \\ ${ }^{3}$ Geological Exploration \& Development Research Institute, CNPC Chuanqing Drilling Engineering Co. Ltd., Chengdu 610051, China
}

Correspondence should be addressed to Fan Zhang; fanz@xsyu.edu.cn

Received 16 November 2020; Revised 29 November 2020; Accepted 14 December 2020; Published 18 January 2021

Academic Editor: Chun Zhu

Copyright (c) 2021 Fan Zhang et al. This is an open access article distributed under the Creative Commons Attribution License, which permits unrestricted use, distribution, and reproduction in any medium, provided the original work is properly cited.

\begin{abstract}
The hard and brittle shale formation is prone to collapse and instability, and the penetration of drilling fluid along the bedding reduces the mechanical properties of rock near the borehole wall, resulting in serious downhole accidents. Therefore, in this paper, the geomechanical parameters of the reservoir in the Longmaxi formation of Jiaoshiba were determined by field hydraulic fracturing and laboratory experiments. Then, the stress distribution model of borehole wall under the condition of underbalanced seepage flow is established based on the experimental results obtained by mechanical experiments on underground cores. The instability zone of borehole wall under the condition of underbalance is calculated and analyzed. The results show that the twoway horizontal ground stress of the Longmaxi formation is higher than $2.2 \mathrm{MPa} / 100 \mathrm{~m}$, and the original ground stress is high. Moreover, the mechanical parameters of the stratified shale stratum matrix and weak surface are significantly different. The cohesion $(4.7 \mathrm{MPa})$ and the angle of internal friction $\left(26.9^{\circ}\right)$ of bedding plane are significantly lower than that of the matrix $(7.77 \mathrm{MPa})$ and the angle of internal friction $\left(46.7^{\circ}\right)$. Hard and brittle shale is easy to be destroyed along the stratification. Under the condition of underbalanced seepage, the mechanical properties of borehole shale can be stable. It is found that when the borehole axis is vertically stratified, the collapse pressure is the lowest, while in other drilling directions, the drilling fluid density needs to be increased by $0.5 \mathrm{~g} / \mathrm{cm}^{3}$ to maintain the borehole stability. With the increase of the inclination angle of bedding plane, the wall failure area increases. The results of this study can provide guidance and suggestions for drilling in Jiaoshiba block and other permeable hard and brittle shale formations.
\end{abstract}

\section{Introduction}

Unconventional oil and gas resources account for about $80 \%$ of the world's oil and gas resources, among which shale oil and gas reservoirs account for a large proportion [1]. Therefore, the effective development of shale oil and gas reservoirs is particularly important. Shale accounts for more than $75 \%$ of the world's drilling, and most of them cause wellbore instability, resulting in drilling costs of more than $\$ 5$ billion per year [2]. The drilling test and production results show that the collapse of the shale section of the Longmaxi formation is very serious in China's Changning-Weiyuan and Ful- ing shale gas demonstration areas [3], so it is necessary to study the wellbore stability of the shale formation in Fuling area. After analysis, the factors affecting wellbore stability of stratified shale mainly include hydration mechanical properties, pore pressure, and in situ stress [4]. Meanwhile, the strength of shale decreases with the time of mud exposure $[5,6]$, especially in the Shale area of the Longmaxi formation $[7,8]$. Moreover, in situ stress is very important for safe drilling [9], and the stress concentration is different from that of isotropic formations on the borehole wall of stratified shale [10]. Among them, the maximum horizontal ground stress has the greatest influence on the stability of shale formation 
[11]. In addition, anisotropic seepage will cause changes in the stress field near the shaft wall $[12,13]$, which will affect the accurate calculation of shaft wall collapse pressure.

Bradley [14] has studied borehole wall instability based on the linear elasticity hypothesis of homogeneous rocks. Subsequently, the problem of borehole wall instability has attracted the attention of researchers all over the world. The influence of strength anisotropy on wellbore stability is not considered in previous models. However, shale contains natural bedding surface, and experimental studies have shown that the failure form of shale with certain stress state is significantly different from that of homogeneous rock [15-20]. Based on the special experimental phenomena of shale, various mathematical models are established to study the instability of shale formation. Hikweon [21] considered the anisotropic strength of shale, converted in situ stress to bedding plane, and the results showed that compared with isotropic formation, the critical collapse pressure of shale formation increased significantly. At the same time, additional stress is generated due to the influence of temperature gradient, and a wellbore stability model with thermal hole elasticity considered is established [22-25].

The influence of anisotropic seepage in shale formation cannot be ignored. The drilling fluid penetrates into the formation along the bedding, changing the stress state around the well and reducing the strength of the rock on the shaft wall $[26,27]$. The Longmaxi formation belongs to the hard and brittle shale, where the water absorption and diffusion coefficient and drilling fluid activity have obvious influences on wellbore expansion and strong sensitivity. Then, the drilling fluid immersion causes instability [28]. For the shale of the Longmaxi formation, water absorption and expansion experiments were carried out [8], and the results showed that hydration effect permeated along the bedding surface, and shale samples were stripped and dropped. As the shale water activity is less than the drilling fluid, in addition to the predicted hydraulic gradient, additional fluids will flow into the shale formation due to the chemical imbalance applied [29]. This creates abnormal pore pressure near the borehole, followed by additional fluid-induced stress, and prolonged exposure to drilling fluid in the wellbore results in reduced strength.

Underbalanced drilling has high efficiency and low cost. In UBD drilling, the bottom hole is completely compressed [30], which can improve the bottom hole seepage capacity and minimize formation damage [31]. In UBD drilling, when considering fluid seepage, the calculation of collapse pressure is more accurate, but the mud density window is narrower [32]. [33, 34] proposed a wellbore stability model of anisotropic strength formation. Before the formation of macroscopic failure surface in the stratigraphic weak plane, sporadic failure occurs in the rock [35]. Previous wellbore stability models failed to predict the damage area around the wellbore. Thus, it is particularly important to accurately calculate and control the area of minor damage.

Therefore, this paper obtained ground stress data of the Longmaxi formation through field hydraulic fracturing combined with laboratory experiments. The mechanical parameters of shale matrix and weak surface were obtained by combining the direct shear test and triaxial compression test. Using these parameters, a wellbore stability model considering anisotropic seepage under the condition of underbalanced drilling is established. The collapse pressure and failure area are analyzed, and the slight failure pattern of wellbore is studied in the same horizon at different shale inclination and inclination angle.

\section{Stress Distribution Model of Shale Formation}

2.1. Coordinate System and Transformation. In the process of establishing the anisotropic wellbore stability model, five reference coordinate systems are needed. These five coordinate systems are called global coordinate systems (GCS), in situ stress coordinate system (ICS), borehole coordinate system (BCS), polar coordinate system (PCS), and facture coordinate system (FCS). The transformation relationship of these coordinate systems is shown in Figures 1 and 2 [36].

In GCS, the positive direction of axis- $X_{n}$ is defined as the geographic North Pole, axis- $Y_{n}$ is defined as East, and axis$Z_{n}$ is perpendicular to the ground. In ICS, this paper stipulates that $X_{o}$ is the horizontal maximum principal stress direction, $Y_{o}$ is the horizontal minimum principal stress direction, and $Z_{o}$ is consistent with GCS. It is worth noting that in the study of $[33,34]$, it is specified that the positive direction of the $x$ -axis is the direction of the minimum horizontal principal stress, while the positive direction of the $y$-axis is the direction of the maximum horizontal principal stress. GCS and ICS for the transformation of the process, according to the right-hand rule, first round $Z_{n}$ shaft turn $\alpha_{o}, Y_{n}$ shaft rotate $\beta_{\mathrm{o}}$ again. The rotation matrix for the transformation from GCS to ICS can be expressed by Equation (1).

$$
M_{N t \mathrm{O}}=\left[\begin{array}{ccc}
\cos \beta_{\mathrm{o}} & 0 & -\sin \beta_{\mathrm{o}} \\
0 & 1 & 0 \\
\sin \beta_{\mathrm{o}} & 0 & \cos \beta_{\mathrm{o}}
\end{array}\right]\left[\begin{array}{ccc}
\cos \alpha_{\mathrm{o}} & \sin \alpha_{\mathrm{o}} & 0 \\
-\sin \alpha_{\mathrm{o}} & \cos \alpha_{\mathrm{o}} & 0 \\
0 & 0 & 1
\end{array}\right] \text {. }
$$

By the same token, GCS and BCS conversion process, $\alpha_{0}$, $\beta_{\mathrm{o}}$ replace $\alpha_{\mathrm{b}}, \beta_{\mathrm{b}}$, including $\alpha_{\mathrm{b}}$ or wellbore azimuth, $\beta_{\mathrm{b}}$ inclination angle, transformation matrix of Equation (2).

$$
M_{N t B}=\left[\begin{array}{ccc}
\cos \alpha_{b} \cos \beta_{b} & \sin \alpha_{b} \cos \beta_{b} & -\sin \beta_{b} \\
-\sin \alpha_{b} & \cos \alpha_{b} & 0 \\
\cos \alpha_{b} \sin \beta_{b} & \sin \alpha_{b} \sin \beta_{b} & \cos \beta_{b}
\end{array}\right] \text {. }
$$

In polar coordinates, $r$ is defined as the distance from the borehole axis to the remote formation, and $\theta$ is the angle that rotates counterclockwise from the axis- $X_{b}$ to the axis- $Y_{b}$, in the borehole rectangular coordinate system. Therefore, from BCS and PCS, you just rotate the BCS about the axis- $Z_{b}$ by $\theta$ , the conversion formula of Equation (3).

$$
M_{B t R}=\left[\begin{array}{ccc}
\cos \theta & \sin \theta & 0 \\
-\sin \theta & \cos \theta & 0 \\
0 & 0 & 1
\end{array}\right]
$$

As shown in Figure 2, FCS is based on the direction of the 


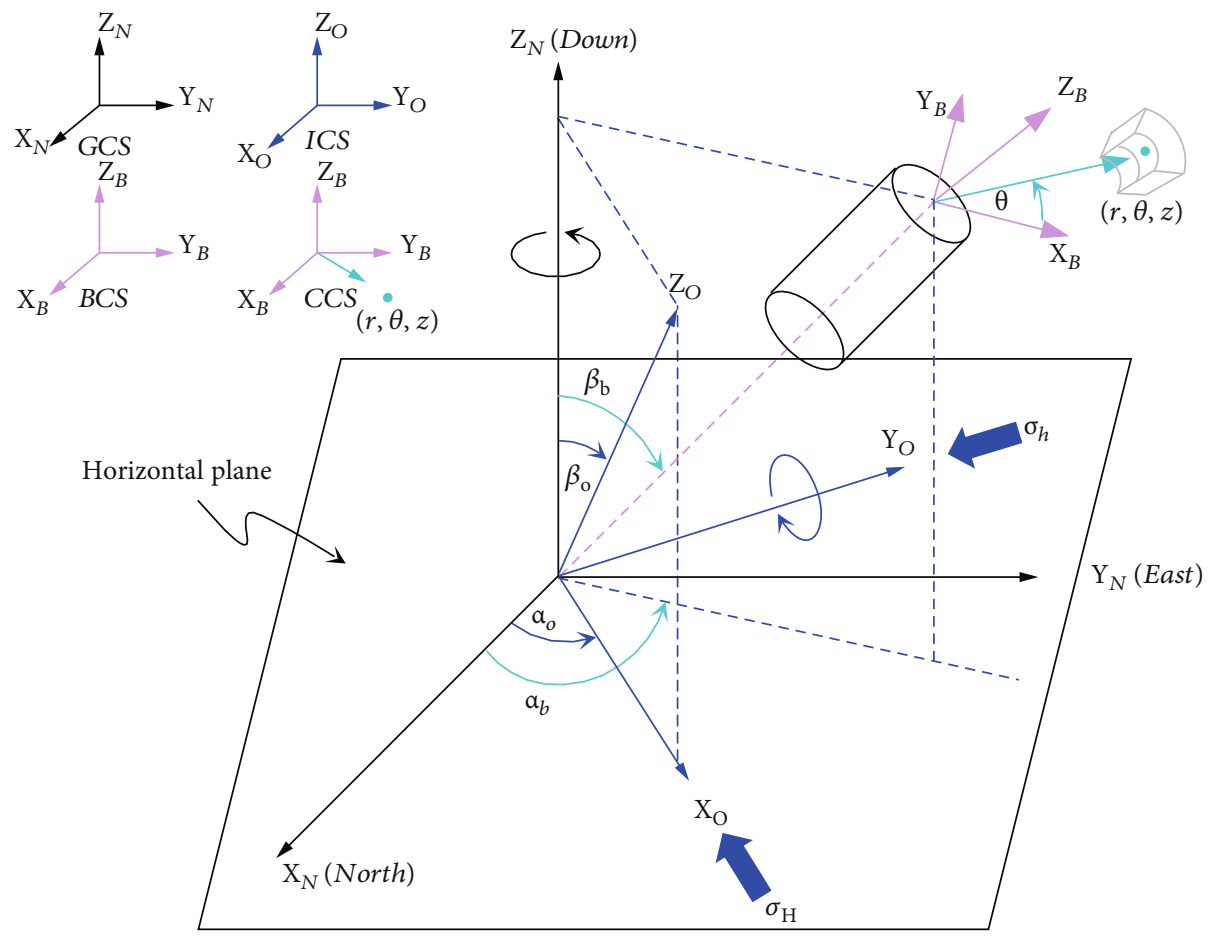

FIgURE 1: The relationship between different coordinate systems.

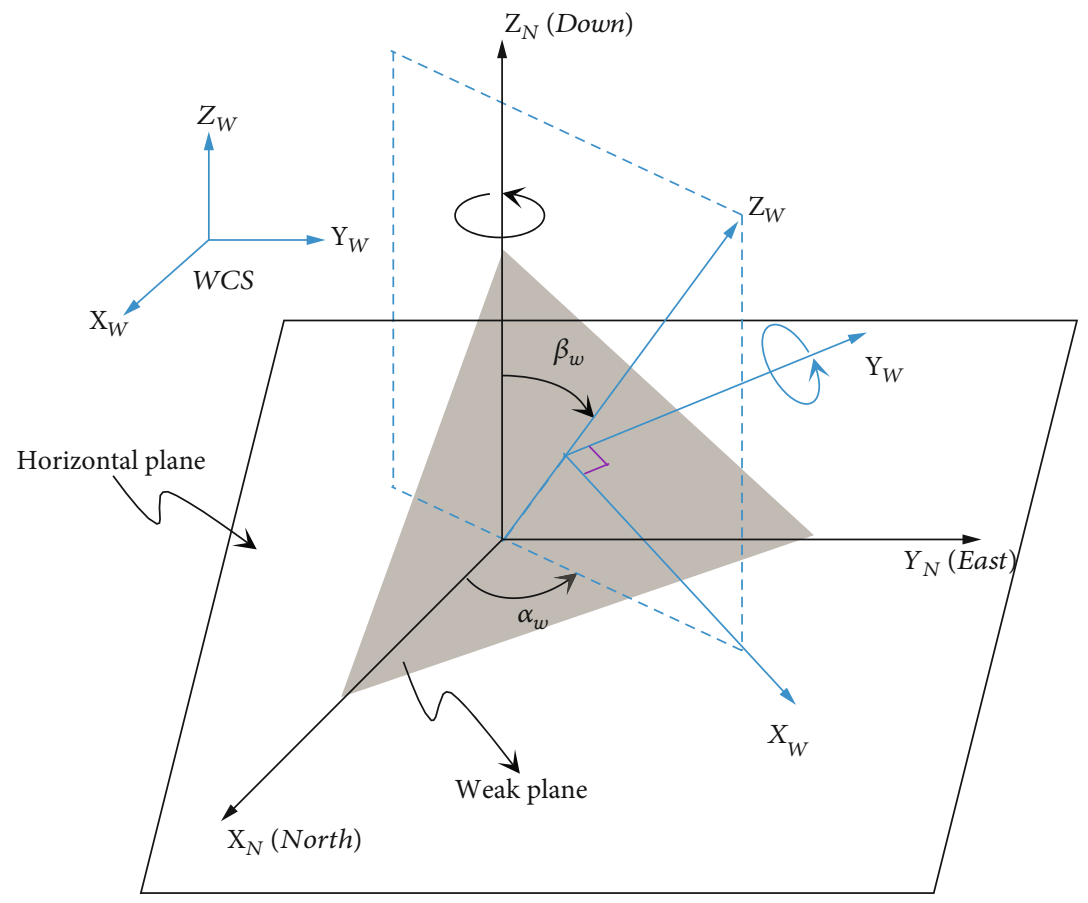

FIGURE 2: The relationship between GCS and WCS. 
weak plane, where $X_{w}$ determines the tendency of the weak plane and $Y_{w}$ is perpendicular to the weak plane at the azimuth angle of the weak plane. $Z_{w}$ is perpendicular to the weak plane. Therefore, the rotation matrix of the transformed stress components from GCS to FCS can be obtained by Equation (4).

$$
M_{N t W}=\left[\begin{array}{ccc}
\cos \beta_{w} \sin \alpha_{w} & \sin \beta_{w} \sin \alpha_{w} & \cos \alpha_{w} \\
-\sin \alpha_{w} & \cos \beta_{w} & 0 \\
-\cos \beta_{w} \cos \alpha_{w} & -\sin \beta_{w} \cos \alpha_{w} & \sin \alpha_{w}
\end{array}\right] .
$$

2.2. Borehole Stress Analysis. As drilling destroys the in situ stress state of the shale formation, in situ stress will form a stress concentration around the wellbore. The conversion process is to convert in situ stresses into GCS and then convert the stress components in the GCS into different stress components in the BCS. The above transformation matrix can be used to represent the mutual transformation of ground stress in different coordinate systems. Therefore, the ground stress component in the BCS can be obtained by using Equation (5).

$$
\sigma_{b c s}=M_{N t B} \times M_{N t O}^{T} \times \sigma_{i c s} \times M_{N t O} \times M_{N t B}^{T} .
$$

Among them, in situ stress is $\sigma_{\mathrm{ics}}=\left\{\sigma_{H}, 0,0 ; 0, \sigma_{h}, 0 ; 0\right.$, $\left.0, \sigma_{v}\right\} . M_{N t O}^{T}$ and $M_{N t B}^{T}$ are the matrix transpose of $M_{N t O}$ and $M_{N t B}$. Based on the stress model around drilling proposed by [14], Equation (6) of elastic isotropic wellbore stress expression is presented. It is worth noting that in this model, when $r=r w$, the model can be simplified to the stress model at the previous shaft wall [34]. Since the radius $r$ from borehole axis to deep formation is retained in this model, the stress state of the formation near the borehole wall can be calculated by the model.

$$
\left\{\begin{array}{l}
\sigma_{r}(\theta, r)=\frac{\sigma_{x}+\sigma_{y}}{2}\left(1-\frac{r_{w}^{2}}{r^{2}}\right)+\left(\frac{\sigma_{x}-\sigma_{y}}{2} \cos 2 \theta+\tau_{x y} \sin 2 \theta\right)\left(1-4 \frac{r_{w}^{2}}{r^{2}}+3 \frac{r_{w}^{4}}{r^{4}}\right) \cos 2 \theta+\frac{r_{w}^{2}}{r^{2}} p_{w}-\alpha p_{p} \\
\sigma_{\theta}(\theta, r)=\frac{\sigma_{x}+\sigma_{y}}{2}\left(1+\frac{r_{w}^{2}}{r^{2}}\right)-\left(\frac{\sigma_{x}-\sigma_{y}}{2} \cos 2 \theta+\tau_{x y} \sin 2 \theta\right)\left(1+3 \frac{r_{w}^{4}}{r^{4}}\right) \cos 2 \theta-\frac{r_{w}^{2}}{r^{2}} p_{w}-\alpha p_{p} \\
\sigma_{z}(\theta, r)=\sigma_{v}-2 \mu \frac{r_{w}^{2}}{r^{2}}\left[\left(\sigma_{x}-\sigma_{y}\right) \cos 2 \theta+2 \tau_{x y} \sin 2 \theta\right]-\alpha p_{p} \\
\tau_{r \theta}(\theta, r)=-\left(\frac{\sigma_{x}-\sigma_{y}}{2} \sin 2 \theta-\tau_{x y} \cos 2 \theta\right)\left(1+2 \frac{r_{w}^{2}}{r^{2}}-3 \frac{r_{w}^{4}}{r^{4}}\right) \\
\tau_{r z}(\theta, r)=\left(\sigma_{x z} \cos \theta+\sigma_{y z} \sin \theta\right)\left(1-\frac{r_{w}^{2}}{r^{2}}\right) \\
\tau_{\theta z}(\theta, r)=\left(\sigma_{y z} \cos \theta-\sigma_{x z} \sin \theta\right)\left(1+\frac{r_{w}^{2}}{r^{2}}\right)
\end{array},\right.
$$

where ${ }_{r}(\theta, r), \sigma_{\theta}(\theta, r), \sigma_{z}(\theta, r), \tau_{r \theta}(\theta, r), \tau_{r z}(\theta, r), \tau_{\theta z}(\theta, r$ ) is the normal and tangential stress of the effective stress components near the wellbore, $r_{w}$ is the borehole radius, and $r$ is the distance from the borehole axis to the distant formation. $P_{p}$ is the formation pressure, which can be affected by formation fluid seepage. $\alpha$ is the Biot's parameter, and $\theta$ is the circumferential angle of the borehole rotation counterclockwise centered on the borehole axis. Equation (6) is used to obtain the tensor of effective stress distribution near the borehole wall, and then, the stress component is converted to the coordinate system FCS in the weak plane by using the formula in Equation (7) $[5,12,34]$.

$$
\begin{aligned}
\sigma_{F C S}= & M_{N t W} \times M_{N t B}^{T} \times M_{B t R}^{T} \\
& \times\left(\begin{array}{ccc}
\sigma_{r}(\theta, \mathrm{r}) & \tau_{r \theta}(\theta, \mathrm{r}) & \tau_{r z}(\theta, \mathrm{r}) \\
\tau_{r \theta}(\theta, \mathrm{r}) & \sigma_{\theta}(\theta, \mathrm{r}) & \tau_{\theta z}(\theta, \mathrm{r}) \\
\tau_{r z}(\theta, \mathrm{r}) & \tau_{\theta z}(\theta, \mathrm{r}) & \sigma_{z}(\theta, \mathrm{r})
\end{array}\right) \\
& \times M_{B t R} \times M_{N t B} \times M_{N t W}^{T} .
\end{aligned}
$$

In the stress component tensor $\sigma_{F C S}$, the normal and shear stresses in the near-wellbore range can be obtained by Equation (8).

$$
\left\{\begin{array}{c}
\sigma_{\mathrm{n} w}(\theta, r)=\sigma_{z}(\theta, r) \\
\tau_{w}(\theta, r)=\sqrt{\tau_{x z}^{2}(\theta, r)+\tau_{y z}^{2}(\theta, r)} \\
f(\theta, r)=0 .
\end{array}\right.
$$

Equation (9) can be established to distinguish rock failure by strength criterion. When Equation (9) is equal to 0 , under a certain drilling fluid density, the value $r$ of borehole circumference radius can be determined when damage occurs at any borehole circumference angle near the borehole wall, and then, the morphological characteristics of borehole wall caving under a certain drilling fluid density can be obtained. For the most part, models were simplified by $r=r_{w}$, bringing the stress of the sidewall into strength criterion to judge whether the rock damage, unable to determine whether wall surrounding rock 
damage due to stress concentration. However, in this model, both the well circumference angle and the distance from the borehole axis radius $r$ are unknown, so the stress state of the rock around the borehole wall can be directly brought into the strength criterion to determine the failure location of the rock around the borehole wall, and then, the failure area and shape of the rock can be obtained.

2.3. Failure Criteria. Most of the existing mechanisms of borehole wall instability are based on the elastic mechanics theory of porous media and rock stability in continuous media is mainly controlled by borehole stress and rock strength. In fractured rock mass, the existence of discontinuous fractures changes the mechanical properties of rock to a large extent, which not only reduces the strength of rock but also reduces the overall cohesion and internal friction angle [18]. It also changes the stress distribution during borehole formation, making surrounding rock more vulnerable to damage. Except for obvious loose or plastic formations, the weak plane criterion is effective in predicting wellbore failure [37]. The weak plane criterion can be expressed as Equation (10).

$$
\sigma_{\theta}-\sigma_{r}=\frac{2\left(C_{w}+\operatorname{tg} \phi_{w} \cdot\left(\sigma_{r}-\alpha \cdot p_{p}\right)\right)}{\left(1-\operatorname{tg} \phi_{w} \cot \beta\right) \sin 2 \beta}
$$

where $\sigma_{\theta}, \sigma_{r}$ are the circumferential stress and the radial stress of borehole wall $(\mathrm{MPa}), C_{W}, \phi_{W}$ are cohesion $(\mathrm{MPa})$ and internal friction angle $\left(^{\circ}\right)$ of weak plane, $P_{P}$ is pore formation stress ( $\mathrm{MPa}), \beta$ is the included angle between the normal direction of fracture surface and the maximum principal stress $\left(^{\circ}\right)$, and $c, \phi$ are cohesion $(\mathrm{MPa})$ and internal friction angle $\left({ }^{\circ}\right)$ of the sample matrix.

According to Equation (7), the maximum and minimum principal stresses of borehole wall are substituted into the formula of weak surface strength criterion (Equation (10)). According to Equation (11), it can be judged whether the shale has shear failure in the rock matrix or sliding failure along the soft surface. The wellbore failure area and failure pattern flow are shown in Figure 3.

$$
\left\{\begin{array}{l}
\beta_{1}=\frac{\varphi_{w}}{2}+\frac{1}{2} \arcsin \left[\frac{\left(\sigma_{1}+\sigma_{3}+2 C_{w} \cot \varphi_{w}\right) \sin \varphi_{w}}{\sigma_{1}-\sigma_{3}}\right] \\
\beta_{2}=\frac{\pi}{2}+\frac{\varphi_{w}}{2}-\frac{1}{2} \arcsin \left[\frac{\left(\sigma_{1}+\sigma_{3}+2 C_{w} \cot \varphi_{w}\right) \sin \varphi_{w}}{\sigma_{1}-\sigma_{3}}\right] \\
2 \beta_{1} \leq 2 \beta \leq 2 \beta_{2}
\end{array}\right.
$$

\section{The Influence of Underbalanced Drilling Seepage Effect}

During UBD operation, the effective fluid column pressure is lower than the formation pore fluid pressure, which means that the fluid flows into the wellbore. Previous studies ignored the influence of fluid seepage. However, the fluid penetrates into the wellbore from the formation and causes additional stress, which affects the wellbore stability to a certain extent.

3.1. Isotropic Seepage Model. Mody [38] first proposed the method of using equivalent pore pressure to evaluate the physical and chemical interaction between mud shale and drilling fluid. Considering the mud shale as isotropic semipermeable membrane, the permeable flow of water in the mud shale is the result of the joint action of pressure potential and chemical potential. The seepage under chemical potential difference can be equivalent to seepage under a certain pressure gradient, and the chemical potential is equivalent to pore pressure (as shown in Equation (12)) [32].

$$
\frac{R T}{V} \ln \left(\frac{\alpha_{\text {shale }}}{\alpha_{\text {mud }}}\right)=P-P_{0}
$$

Here, $R$ is the perfect gas constant, $T$ is the absolute temperature $(\mathrm{K}), V$ is the partial molar volume of water $(1 / \mathrm{mole})$, $\alpha_{\text {shale }}$ is the activity of water for pore fluid, $\alpha_{m u d}$ is the activity of water for drilling mud, $P$ is pore pressure $(\mathrm{MPa})$, and $P_{0}$ is the original pore pressure $(\mathrm{MPa})$.

3.2. Anisotropic Seepage Model. The permeability of stratified shale is different between vertical stratification and along stratification. Therefore, the effect of anisotropic seepage on pore pressure is different from that of isotropic formation and, thus, affects the stress field near the borehole wall [39]. On the basis of isotropic seepage research, the Darcy formula can be expressed as Equation (13) when considering the seepage anisotropy of stratified strata.

$$
\left\{\begin{array}{l}
q_{x}=-\frac{1}{\mu}\left(k_{x x} \frac{\partial p}{\partial x}+k_{x y} \frac{\partial p}{\partial y}+k_{x z} \frac{\partial p}{\partial z}\right) \\
q_{y}=-\frac{1}{\mu}\left(k_{y x} \frac{\partial p}{\partial x}+k_{y y} \frac{\partial p}{\partial y}+k_{y x} \frac{\partial p}{\partial z}\right) \\
q_{z}=-\frac{1}{\mu}\left(k_{z x} \frac{\partial p}{\partial x}+k_{z x} \frac{\partial p}{\partial y}+k_{z z} \frac{\partial p}{\partial z}\right)
\end{array}\right.
$$

where $q_{x}, q_{y}, q_{z}$ is the seepage velocity ( $\left.\mathrm{m} / \mathrm{s}\right), k_{i i}$ is permeability in all directions (D), $\mu$ is fluid viscosity (mPa.s), and $p$ is formation pressure ( $\mathrm{MPa})$. Therefore, anisotropic permeability can be expressed as tensor from Equation (14).

$$
k=\left[\begin{array}{lll}
k_{x x} & k_{x y} & k_{x z} \\
k_{y x} & k_{y y} & k_{y z} \\
k_{z x} & k_{z y} & k_{z z}
\end{array}\right] .
$$

It can be seen that the permeability tensor has a similar expression form to the stress tensor and is also a symmetric tensor. The permeability tensor has properties similar to those of the stress tensor and can be expressed as an assertion 


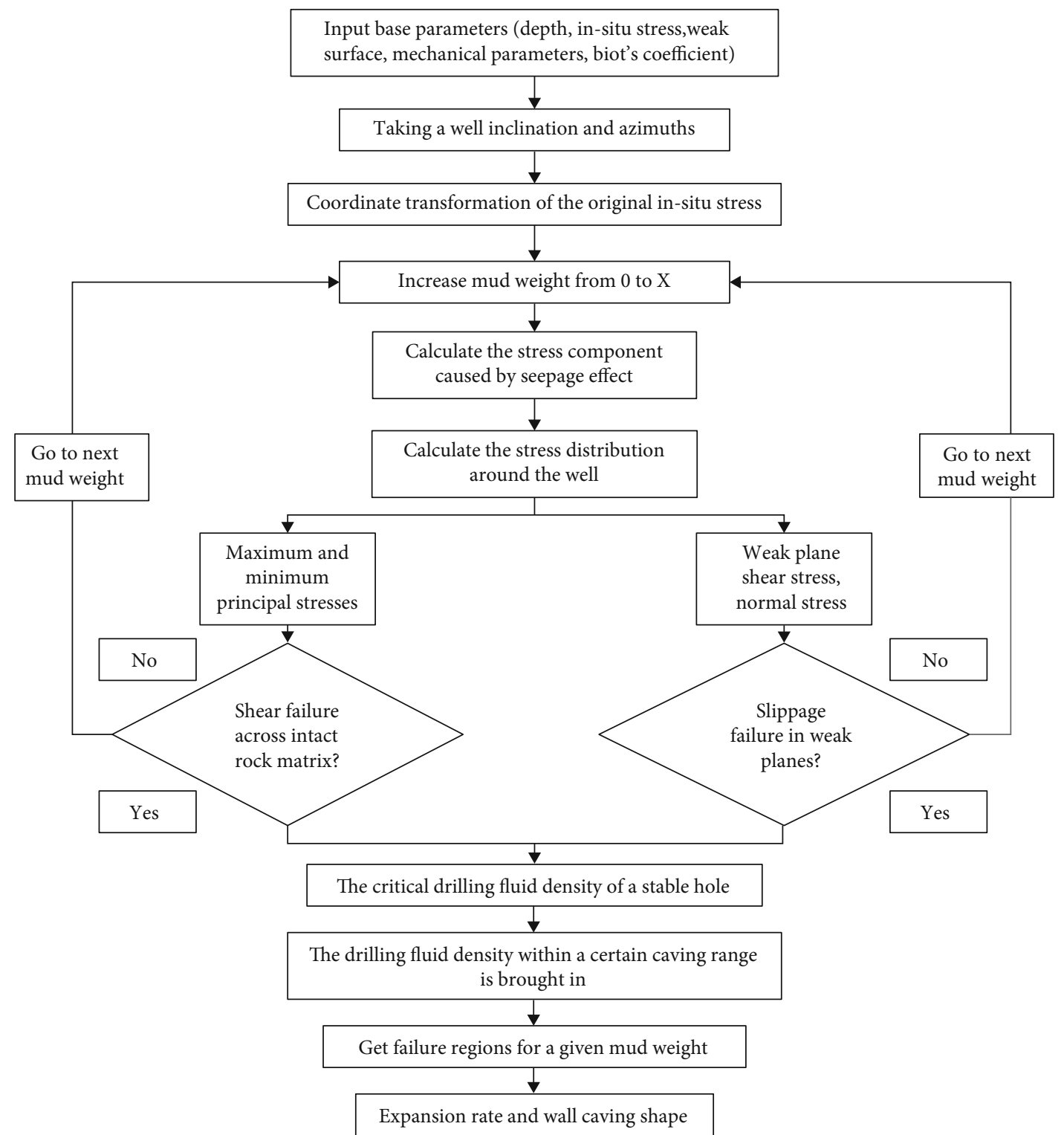

FIGURE 3: Flow chart of the borehole wall and surrounding instability area.

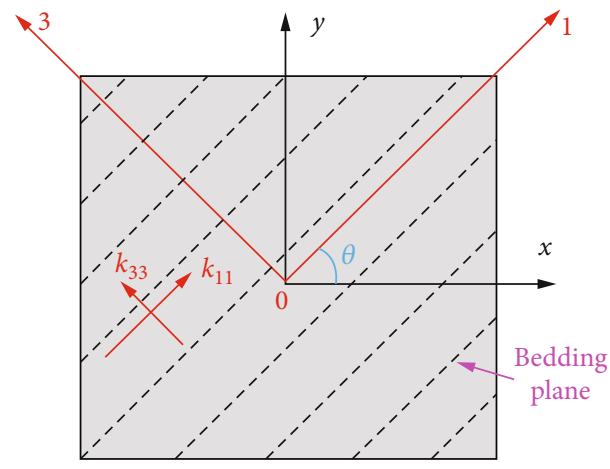

FIgURE 4: Schematic diagram of the relationship between the main direction of penetration and stratification. in relation to the principal stress form of the stress. The permeability assertion is expressed as follows Equation (15).

$$
k=\left[\begin{array}{ccc}
k_{x} & 0 & 0 \\
0 & k_{y} & 0 \\
0 & 0 & k_{z}
\end{array}\right]
$$

When the local layer contains obvious bedding, the main direction of penetration can be expressed as the permeability along the bedding and perpendicular to the bedding. The relationship between the permeability and the bedding structure is shown in Figure 4.

In particular, for stratified strata, the same flow characteristics are often found within the same bedding plane. Therefore, the pressure transfer around the well can be 
regarded as a plane problem. Therefore, Darcy's twodimensional anisotropy formula can be expressed as Equation (16).

$$
\left\{\begin{array}{l}
q_{x}=-\frac{1}{\mu}\left(k_{x x} \frac{\partial p}{\partial x}+k_{x y} \frac{\partial p}{\partial y}\right) \\
q_{y}=-\frac{1}{\mu}\left(k_{y x} \frac{\partial p}{\partial x}+k_{y y} \frac{\partial p}{\partial y}\right)
\end{array} .\right.
$$

When the permeability spindle coincides with the coordinate axis, the permeability tensor can be written as Equation (17).

$$
k=\left[\begin{array}{cc}
k_{11} & 0 \\
0 & k_{33}
\end{array}\right] .
$$

According to the measurement of vertical bedding and permeability along the bedding, the additional stress on the formation under different borehole conditions can be obtained by Equation (18).

$$
P_{\mathrm{ij}}=P_{w}+\left(P_{p}-P_{w}\right) \operatorname{erf}\left(\frac{r k_{i j}}{4 \Phi \mu C_{t} t}\right),
$$

where $P_{\mathrm{ij}}$ is the pore pressure of any well trajectory $(\mathrm{MPa}), \Phi$ is porosity (\%), $r$ is distance from borehole center to far sidewall (m), $\mu$ is the viscosity of the pore fluid (D), $C_{t}$ is fluid compressibility, and $t$ is time (s).

\section{Borehole Stability and Caving under Underbalanced Condition}

The in situ stress state of the Longmaxi formation was determined by on-site hydraulic fracturing and laboratory experiment, and the downhole core was subjected to triaxial compression experiment to obtain the mechanical parameters of shale matrix. The layered shale was subjected to direct shear test, and the cohesion and internal friction angle of the shale weak surface were obtained by using the mole line [39]. On this basis, the minimum mud density and the unstable region under different bedding distribution considering the seepage effect are studied.

4.1. Geological Mechanics and Rock Mechanics Parameters of the Longmaxi Formation. Horizontal in situ stress values are calculated using hydraulic fracturing data. Hydraulic pressure method calculates ground stress according to hole's stress state and fracture mechanism. The hydraulic pressure overcomes the ultimate tensile strength of the formation and causes it to break, causing fractures. Fracturing fluid enters the formation and causes a sudden drop in pressure. When the fracture extends beyond the wellbore stress concentration area, the pump is stopped instantaneously, and the pressure value is the minimum horizontal ground stress. The maximum horizontal ground stress is calculated by opening the fracture again by opening the pump. And the laboratory in situ stress experiment measured the horizontal maximum and horizontal minimum in situ stress through the Kaiser effect of the rock. Through field test of hydraulic fracturing in the formation of the Longmaxi formation and laboratory experiment, horizontal ground stress in this area is obtained (as shown in Table 1).

In order to obtain more practical mechanical properties of layered strata, triaxial rock mechanics experiment and direct shear test were carried out with the research object of underground shale and surface outcrop in the Longmaxi formation. At the same time, according to the field logging data, the main parameters required by the model are obtained (as shown in Table 2).

4.2. Underbalanced Drilling Collapse Pressure. Under the condition of underbalanced drilling, the stress around the well has changed. Although the permeability of shale formation is low, it is not a nonpermeable formation. When considering both the weak plane of bedding and the condition of underbalance, the collapse pressure of the Longmaxi formation block has been studied.

By comparing and analyzing the distribution law of the collapse pressure around the well with different bedding inclination angles of $30^{\circ}$ and $60^{\circ}$, it is found that along the direction of bedding inclination or its relative direction, the collapse pressure is generally low, while on the direction with an included angle of $90^{\circ}$ with the bedding inclination, the collapse pressure generally reaches its maximum. In addition, the distribution law of collapse pressure is also different for different beddings. In the direction of bedding inclination, the minimum value is generally obtained at the position of inclination angle corresponding to the bedding inclination angle. While drilling horizontal wells in other directions, the drilling fluid density is usually increased by more than $0.5 \mathrm{~g} / \mathrm{cm}^{3}$ to maintain borehole stability (as shown in Figures 5 and 6).

The above figure shows that different bedding plane profiles have a significant influence on the collapse pressure density. When the inclination angle of bedding plane is $30^{\circ}$ and the inclination direction is $0^{\circ}$, the collapse pressure of the shaft wall is the largest when the inclination angle of borehole is $0-10^{\circ}$, so it is necessary to pay attention to prevent collapse in drilling straight wells under this condition. With the increase of the inclination angle of borehole, the law of collapse pressure on different azimuth angles of borehole is different. When the azimuth angle of borehole is $90^{\circ}$ and $270^{\circ}$, the collapse occurs always in high pressure, above $1.7 \mathrm{~g} / \mathrm{cm}^{3}$. The collapse pressure decreases gradually with the increase of well inclination angle in the range of azimuth $330-30^{\circ}$ and $150-210^{\circ}$. In this range, when the inclination angle of borehole exceeds $20^{\circ}$, the collapse pressure will decrease significantly, with an average decrease of 0.2-0.3. Special attention is paid to the fact that the minimum collapse pressure is $1.2 \mathrm{~g} / \mathrm{cm}^{3}$ when the azimuth angle of borehole is $15^{\circ}$ and the inclination angle of borehole is $30^{\circ}$. When the inclination angle of bedding plane is $30^{\circ}$ and the inclination direction is $30^{\circ}$, the collapse pressure distribution has changed significantly. In the same way, the azimuth angle of borehole $90^{\circ}$ and $270^{\circ}$ direction to achieve maximum value, but the area where the collapse pressure is decreasing 
TABLE 1: The horizontal ground stress was determined by field and laboratory experiments.

\begin{tabular}{lccc}
\hline Parameters & Field hydraulic fracturing & Laboratory experiment & Average value \\
\hline Maximum horizontal stress gradient $\left(\mathrm{g} / \mathrm{cm}^{3}\right)$ & 2.73 & 2.87 & 2.80 \\
Minimum horizontal stress gradient $\left(\mathrm{g} / \mathrm{cm}^{3}\right)$ & 2.24 & 2.18 & 2.21 \\
\hline
\end{tabular}

TABLE 2: Mechanical parameters of stratigraphic foundation of the Longmaxi formation.

\begin{tabular}{lccc}
\hline Parameters & Value & Parameters & Value \\
\hline Depth $(\mathrm{m})$ & 2450 & Cohesion of rock matrix $(\mathrm{MPa})$ & 7.77 \\
Vertical stress gradient $\left(\mathrm{g} / \mathrm{cm}^{3}\right)$ & 2.61 & Friction angle of rock matrix (Deg) & 46.7 \\
Pore formation stress gradient $\left(\mathrm{g} / \mathrm{cm}^{3}\right)$ & 1.15 & Cohesion of shale bedding (MPa) & 4.7 \\
Biot's coefficient & 0.45 & Friction angle of shale bedding (Deg) & 26.9 \\
Elastic modulus $(\mathrm{GPa})$ & 22.0 & Poisson's ratio & 0.21 \\
\hline
\end{tabular}

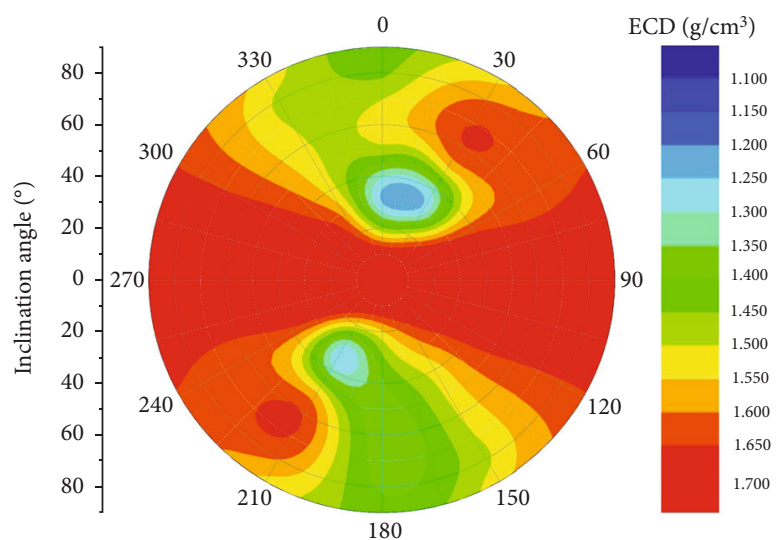

Wellbore azimuth $\left({ }^{\circ}\right)$ Inclination direction $(\alpha)=0^{\circ}$
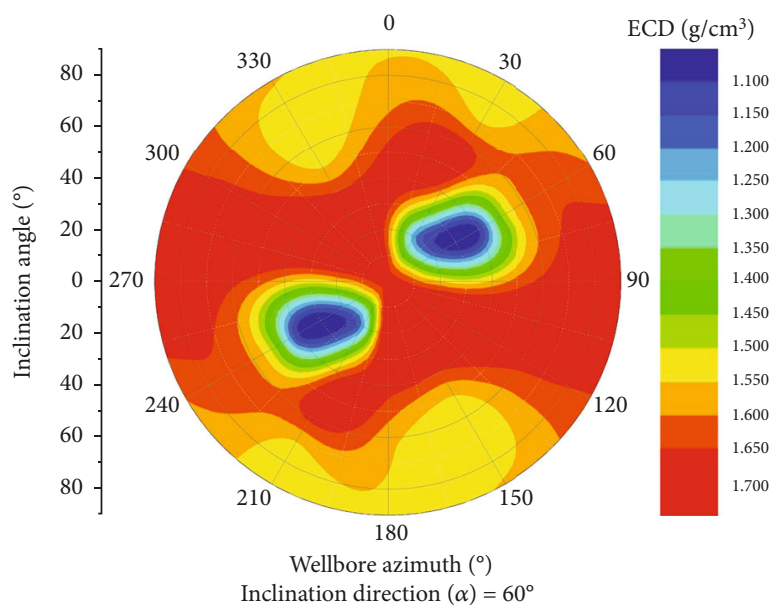
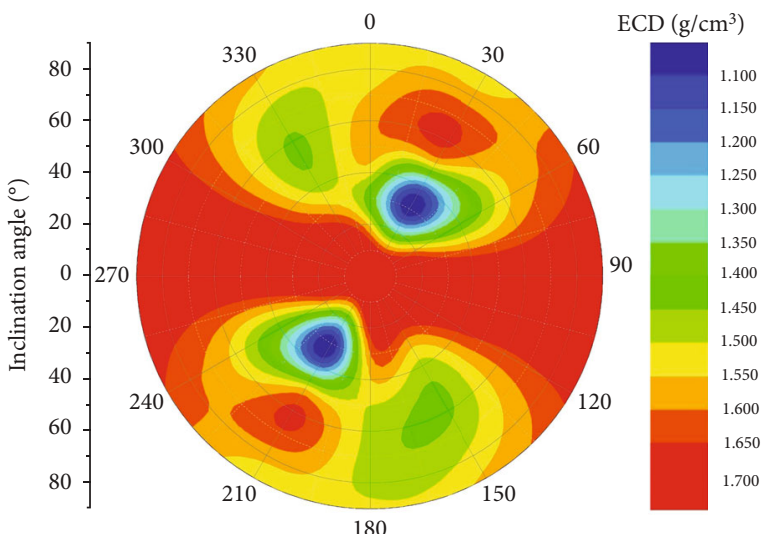

Wellbore azimuth $\left({ }^{\circ}\right)$ Inclination direction $(\alpha)=30^{\circ}$
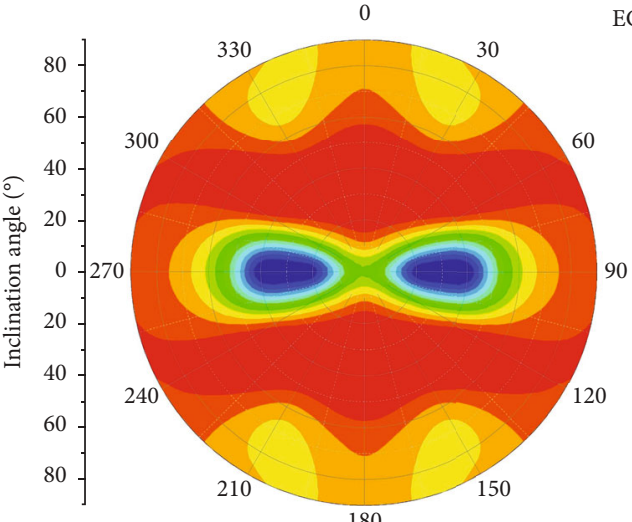

$\operatorname{ECD}\left(\mathrm{g} / \mathrm{cm}^{3}\right)$

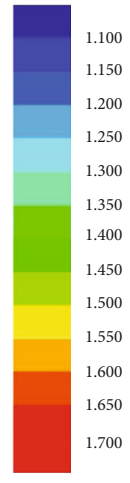

Wellbore azimuth $\left(^{\circ}\right)$

Inclination direction $(\alpha)=90^{\circ}$

FIgURE 5: The inclination angle of bedding plane is $30^{\circ}$.

expands. Directional wells with a certain angle can be drilled within the azimuth range of $320-70^{\circ}$ and $140-250^{\circ}$. In particular, in the azimuth angle of borehole of $30^{\circ}$ and $210^{\circ}$, the collapse pressure first decreases, then increases, and then decreases. The minimum value of collapse pressure is $1.1 \mathrm{~g} / \mathrm{cm}^{3}$ when the inclination angle of borehole is about $30^{\circ}$. When the inclination angle of bedding plane is $30^{\circ}$ and the inclination direction is $60^{\circ}$, the collapse pressure is rela- tively low in the range of azimuth angle of borehole of 30$75^{\circ}$ and $210-255^{\circ}$, and the well inclination angle is lower than $60^{\circ}$. While in other directions, the collapse pressure is higher, averaging around $1.6 \mathrm{~g} / \mathrm{cm}^{3}$. At the inclination angle of bedding plane of $30^{\circ}$ and the inclination direction of $90^{\circ}$, the collapse pressure along the azimuth angle of borehole of $90^{\circ}$ and $270^{\circ}$ is small, but when the well inclination angle exceeds $60^{\circ}$, the collapse pressure will increase significantly. While in the 

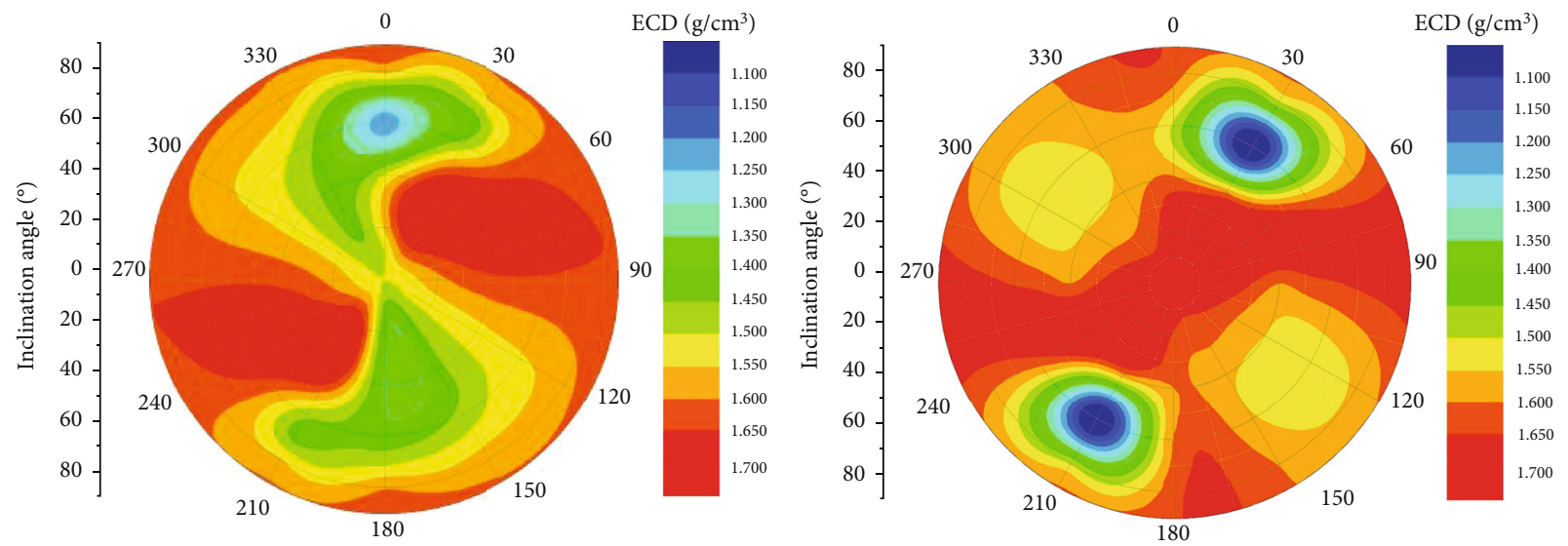

Wellbore azimuth $\left({ }^{\circ}\right)$

Inclination direction $(\alpha)=0^{\circ}$
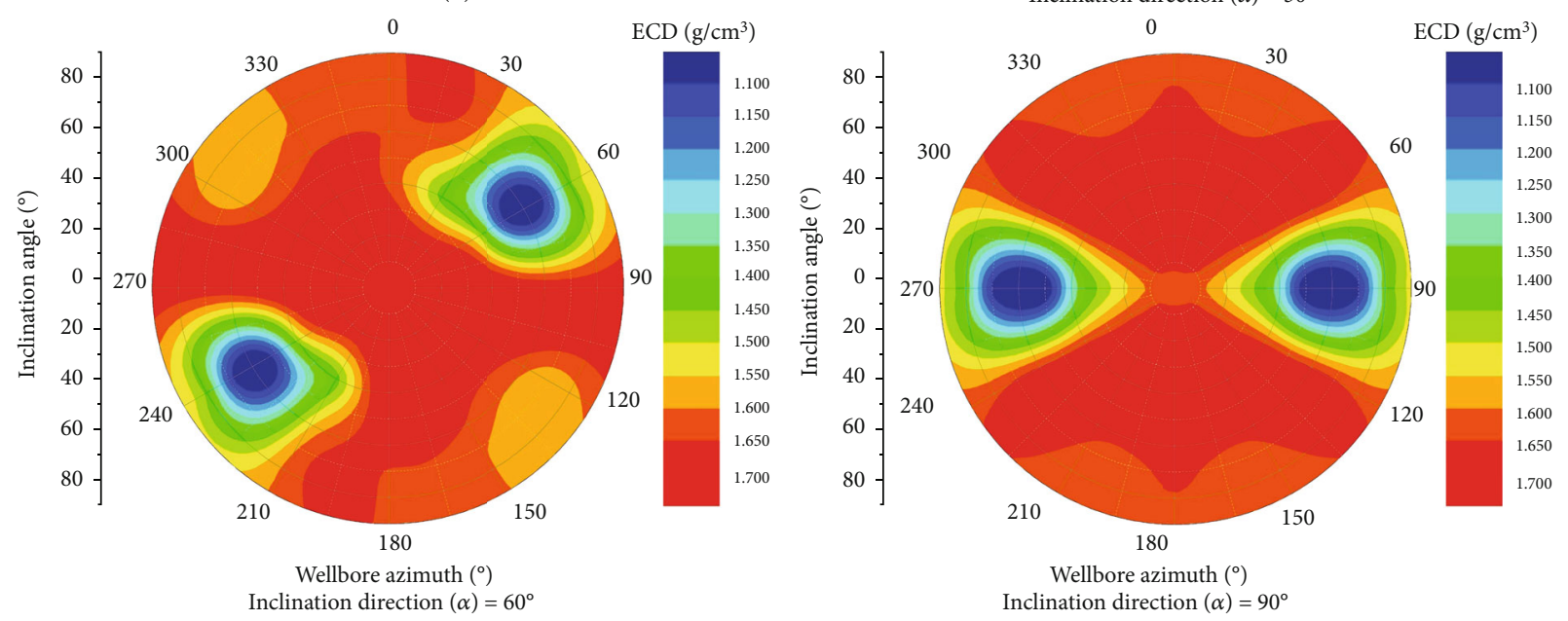

Figure 6: The inclination angle of bedding plane is $60^{\circ}$.

azimuth angle of borehole of $0^{\circ}$ and $180^{\circ}$, the maximum collapse pressure is more than $1.7 \mathrm{~g} / \mathrm{cm}^{3}$.

Compared with the inclination angle of bedding plane of $30^{\circ}$, when the bedding dip angle is $60^{\circ}$, the distribution law of collapse pressure will change significantly. When the bedding tendency is $0^{\circ}$, in the azimuth range of $120-180^{\circ}$ and 300 $360^{\circ}$, the collapse pressure density is relatively low, and the directional hole with the drilling inclination angle less than $80^{\circ}$ is relatively stable. In the azimuth angle of borehole of $45^{\circ}$ and $225^{\circ}$, the collapse pressure is relatively large, generally above $1.6 \mathrm{~g} / \mathrm{cm}^{3}$. When the bedding tendency is $30^{\circ}$ and the azimuth angle is $30^{\circ}$ and $210^{\circ}$, the collapse pressure is above $1.6 \mathrm{~g} / \mathrm{cm}^{3}$ with a small inclination angle of borehole. With the increase of the well inclination angle, the collapse pressure will gradually decrease. When the inclination angle of borehole is $60^{\circ}$, the collapse pressure drops to $1.1 \mathrm{~g} / \mathrm{cm}^{3}$, a decrease of $0.5 \mathrm{~g} / \mathrm{cm}^{3}$. When the bedding tendency is $60^{\circ}$, the collapse pressure is lower in the azimuths of $60^{\circ}$ and $240^{\circ}$. While in other directions, the collapse pressure is above $1.5 \mathrm{~g} / \mathrm{cm}^{3}$. When the bedding tendency is $90^{\circ}$, the collapse pressure along the azimuth direction $90^{\circ}$ and $270^{\circ}$ is lower, and when the inclination angle of the well in this direction exceeds $30^{\circ}$, the borehole is generally stable.
Therefore, the bedding occurrence has a great influence on the collapse pressure distribution. In the drilling construction process, the distribution of bedding occurrence should be noted to determine the optimal drilling construction parameters.

4.3. Unbalanced Drilling Wellbore Failure Zone. During drilling, the design of collapse pressure density provides a favorable guarantee. However, when the borehole wall collapse occurs, the situation of borehole wall instability is often unclear. Therefore, based on the results of the abovementioned collapse pressure, the collapse characteristics of the bedding strata in the Longmaxi formation are studied (as shown in Figures 7 and 8).

According to Figure 7, when the dip angle of the weak surface is $30^{\circ}$, the caving patterns of shaft walls with different azimuths are greatly different. When the tendency of bedding surface is $30^{\circ}$, if the borehole wall collapses or brittle caving occur, the diameter will be expanded along the well circumference angles of $75^{\circ}, 165^{\circ}, 255^{\circ}$, and $345^{\circ}$, and the degree of caving along the four directions will be roughly equal. When the bedding azimuth angle is $45^{\circ}$, the caving point will rotate clockwise, and the amount of caving along the directions of $0^{\circ}$ 


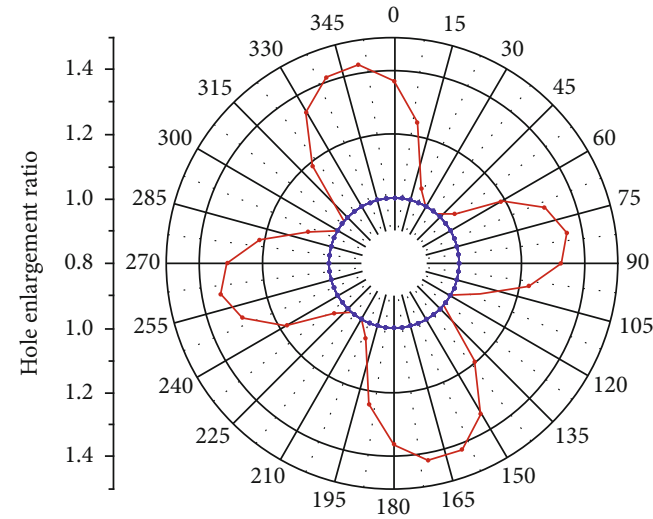

The angle of the borehole circumference Inclination direction $(\alpha)=30^{\circ}$ - Instability $\longrightarrow$ Original

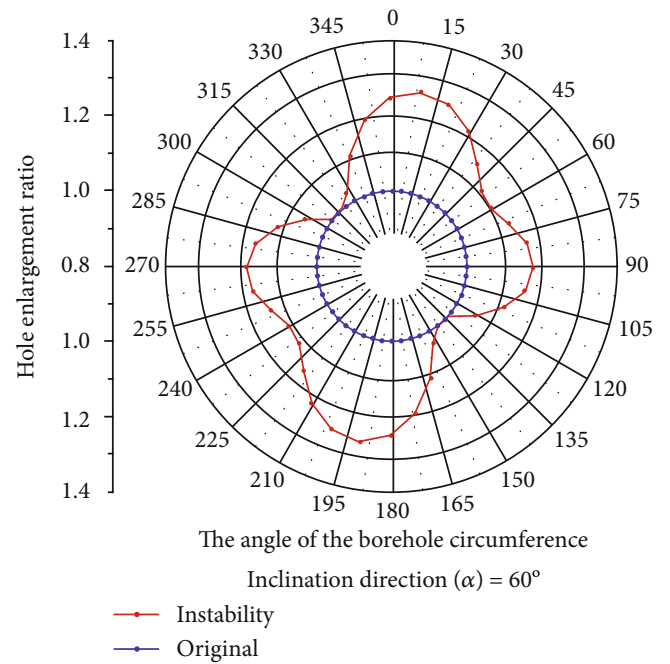

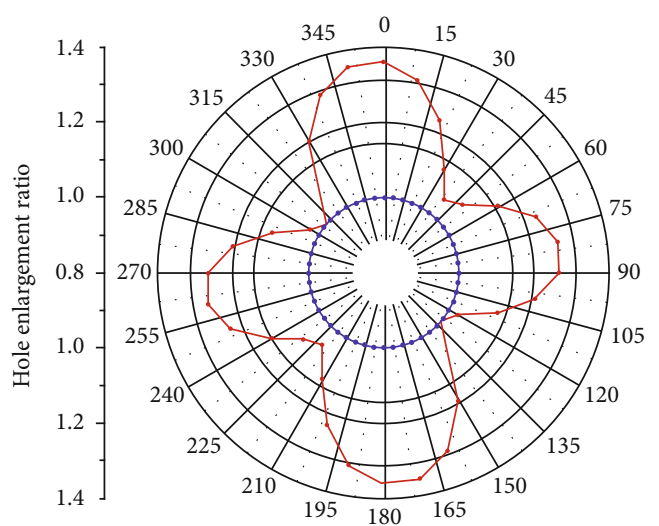

The angle of the borehole circumference Inclination direction $(\alpha)=45^{\circ}$

$\rightarrow$ Instability

- Original

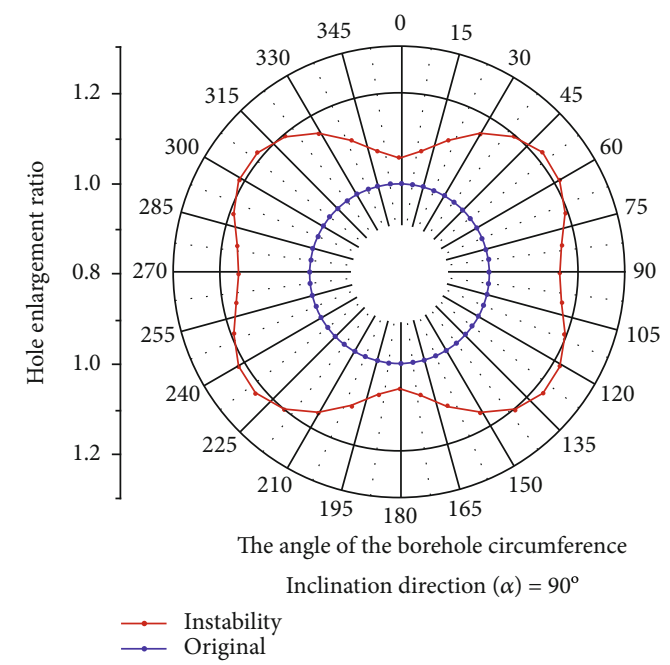

FIgURE 7: Characteristic shape of wellbore caving at $30^{\circ}$ inclination angle of bedding plane.

and $180^{\circ}$ will exceed the other two directions. When the inclined azimuth angle of bedding plane is $60^{\circ}$, the shape characteristics of shaft wall caving will change further. The degree of caving will decrease in the direction of $15^{\circ}$ and $195^{\circ}$, and the degree of caving will increase in the direction of $90^{\circ}$ and $180^{\circ}$. When the bedding inclination azimuth is $90^{\circ}$, the sidewall will collapse along the perimeter, in which case the sidewall will expand along the perimeter. It can be seen from Figure 8 that when the bedding inclination angle is $60^{\circ}$, when the inclination azimuth of the bedding plane is $30^{\circ}, 45^{\circ}$, and $60^{\circ}$, the shaft wall will collapse along the four perpendicular directions, and the collapse scale is roughly the same. With the increase of the bedding inclination azimuth angle, the collapse direction will rotate clockwise. When the bedding tendency is $90^{\circ}$, the shaft wall will collapse along the directions of $45^{\circ}, 135^{\circ}, 225^{\circ}$, and $315^{\circ}$, and the amount of collapse is basically the same. On the whole, the caving is more regular when the bedding surface dip angle is $60^{\circ}$ than $30^{\circ}$. It can be concluded that the anisotropy of bedding has a great influence on the shape characteristics of shaft wall caving, and the shape of shaft wall caving should be analyzed according to the specific formation conditions.

\section{Conclusion}

In order to solve the prominent problem of borehole instability in shale formation in the Jiaoshiba area, a collapse pressure calculation model and a model of well cycle instability area are proposed, which take into account the underbalanced seepage flow condition and anisotropy of rock strength. According to the depth of the unstable section of the shaft wall, the in situ stress parameters of the Longmaxi formation were obtained by hydraulic fracturing and laboratory test. It is generally considered that high ground stress is greater than $2 \mathrm{MPa} / 100 \mathrm{~m}$. The results show that the two-way horizontal ground stress is higher than $2.2 \mathrm{MPa} / 100 \mathrm{~m}$, so the original ground stress of the rational stratum of the Longmaxi formation is in a state of high stress.

Through downhole core mechanics experiments, the mechanical parameters of the shale matrix and the weak surface of the bedding were obtained, indicating that the cohesion and internal friction angle of the bedding surface $\left(4.7 \mathrm{MPa}, 26.9^{\circ}\right)$ were significantly lower than that of the rock body $\left(7.77 \mathrm{MPa}, 46.7^{\circ}\right)$. Combined with the site, the 

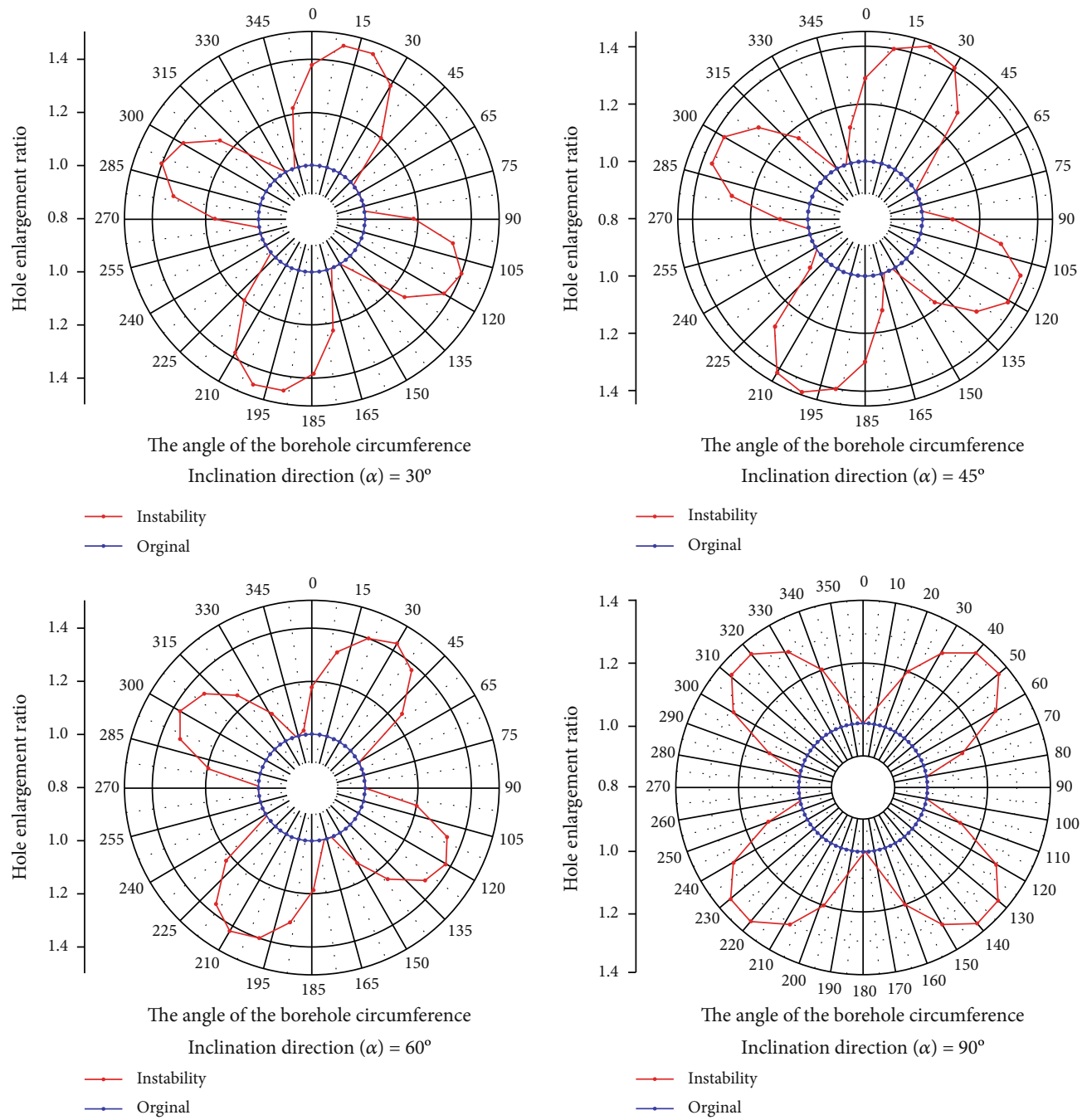

FIGURE 8: Characteristic shape of wellbore caving at $60^{\circ}$ inclination angle of bedding plane.

stratigraphy of the Longmaxi Formation is developed, which is prone to loss during drilling, and the permeability of shale matrix is low. Therefore, it is believed that the drilling fluid mainly intruded along the stratigraphy. At the same time, the mechanical parameters of bedding surface are obviously lower than that of rock matrix, which further affects the stability of wellbore. It is considered that underbalanced drilling can reduce the damage of drilling fluid to near-wellbore formation and improve the stability.

For horizontal wells, the collapse pressure law of different bedding occurrences (inclination angle and tendency) is studied. Generally, the minimum value is obtained at the inclined angle position of the well corresponding to the bedding inclination angle, that is, when the borehole axis is perpendicular to the bedding plane. Otherwise, the drilling fluid density is often increased by $0.5 \mathrm{~g} / \mathrm{cm}^{3}$ in other directions to maintain borehole stability. The bedding occurrence has a great influence on the collapse pressure distribution. During drilling construction, the distribution of bedding occurrence must be noted to determine the most accurate drilling construction parameters.
In this paper, the characteristics of wellbore instability in bedding strata are studied. When the bedding dip angle is low, during the rotation of the bedding tendency from the direction of maximum horizontal ground stress to the direction of minimum horizontal ground stress, the shaft wall collapse pattern begins with several specific directions and then collapses uniformly around the well. With the increase of bedding angle, the diameter expansion rate also increases gradually. Therefore, it is necessary to understand the collapse state more clearly when the wellbore collapses in the stratified formation, so as to provide the basis for safe production and accident treatment.

\section{Data Availability}

The data used to support the findings of this study are available from the corresponding author upon request.

\section{Conflicts of Interest}

The authors declare that they have no conflicts of interest. 


\section{Acknowledgments}

The authors are grateful to Dr. Shuai Cui and anonymous reviewers for their constructive comments that substantially improved the manuscript. This research was financially supported by the Open Fund of Shaanxi Key Laboratory of Advanced Stimulation Technology for Oil \& Gas Reservoirs, grant number 20JS120; Young science and Technology Talents Foundation of Shaanxi province, grant number 2019KJXX-054; and National Natural Science Foundation of China, grant numbers $(41702146,51934005,51874242)$.

\section{References}

[1] C. Zou, Z. Guangming, G. Zhang et al., "Formation, distribution, potential and prediction of global conventional and unconventional hydrocarbon resources," Petroleum Exploration and Development, vol. 42, no. 1, pp. 14-28, 2015.

[2] K. Duan and C. Y. Kwok, "Evolution of stress-induced borehole breakout in inherently anisotropic rock: insights from discrete element modeling," Journal of Geophysical Research: Solid Earth, vol. 121, no. 4, pp. 2361-2381, 2016.

[3] L. Houbin, Z. Fan, M. Yingfeng, L. Gao, and C. Yunhai, "Experimental study on wellbore stability of shale gas reservoir for horizontal well in Jiaoshiba area," Chinese Journal of Underground Space and Engineering, vol. 13, no. 6, pp. 15311536, 2017.

[4] L. Ding, Z. Wang, B. Liu, J. Lv, and Y. Wang, "Borehole stability analysis: a new model considering the effects of anisotropic permeability in bedding formation based on poroelastic theory," Journal of Natural Gas Science and Engineering, vol. 69, article 102932, 2019.

[5] T. Ma and P. Chen, "A wellbore stability analysis model with chemical-mechanical coupling for shale gas reservoirs," Journal of Natural Gas Science and Engineering, vol. 26, pp. 7298, 2015.

[6] Y. I. Ding, P. Luo, X. Liu, and L. Liang, "Wellbore stability model for horizontal wells in shale formations with multiple planes of weakness," Journal of Natural Gas Science and Engineering, vol. 52, pp. 334-347, 2018.

[7] X. Li, X. Yan, and Y. Kang, "Investigation of drill-in fluids damage and its impact on wellbore stability in Longmaxi shale reservoir," Journal of Petroleum Science and Engineering, vol. 159, pp. 702-709, 2017.

[8] L. Liang, J. Xiong, and X. Liu, "Experimental study on crack propagation in shale formations considering hydration and wettability," Journal of Natural Gas Science and Engineering, vol. 23, pp. 492-499, 2015.

[9] R. Gholami, M. Rabiei, V. Rasouli, B. Aadnoy, and N. Fakhari, "Application of quantitative risk assessment in wellbore stability analysis," Journal of Petroleum Science and Engineering, vol. 135, pp. 185-200, 2015.

[10] R. Weijermars, J. Wang, and R. Nelson, "Stress concentrations and failure modes in horizontal wells accounting for elastic anisotropy of shale formations," Earth-Science Reviews, vol. 200, article 102957, 2020.

[11] A. Abdollahipour, H. Soltanian, Y. Pourmazaheri, E. Kazemzadeh, and M. Fatehi-Marji, "Sensitivity analysis of geomechanical parameters affecting a wellbore stability," Journal of Central South University, vol. 26, no. 3, pp. 768-778, 2019.
[12] J. Zhou, S. He, M. Tang et al., "Analysis of wellbore stability considering the effects of bedding planes and anisotropic seepage during drilling horizontal wells in the laminated formation," Journal of Petroleum Science and Engineering, vol. 170, pp. 507-524, 2018.

[13] X. Li, H. Jaffal, Y. Feng, C. el Mohtar, and K. E. Gray, "Wellbore breakouts: Mohr-Coulomb plastic rock deformation, fluid seepage, and time-dependent mudcake buildup," Journal of Natural Gas Science and Engineering, vol. 52, pp. 515-528, 2018.

[14] W. B. Bradley, "Failure of Inclined Boreholes," Journal of Energy Resources Technology, vol. 101, no. 4, pp. 232-239, 1979.

[15] S. Heng, X. Li, X. Liu, and Y. Chen, "Experimental study on the mechanical properties of bedding planes in shale," Journal of Natural Gas Science and Engineering, vol. 76, article 103161, 2020.

[16] J. Zuo, J. Lu, R. Ghandriz et al., "Mesoscale Fracture Behavior of Longmaxi Outcrop Shale with Different Bedding Angles: Experimental and Numerical Investigations," Journal of Rock Mechanics and Geotechnical Engineering, vol. 12, no. 2, pp. 297-309, 2020.

[17] Y. Suo, Z. Chen, S. S. Rahman, and X. Chen, "Experimental study on mechanical and anisotropic properties of shale and estimation of uniaxial compressive strength," Energy Sources, Part A: Recovery, Utilization, and Environmental Effects, pp. $1-11,2020$.

[18] W. Guo, W. Shen, X. Li et al., "Study on mechanical characteristics and damage mechanism of the Longmaxi Formation shale in southern Sichuan Basin, China," Energy Exploration \& Exploitation, vol. 38, no. 2, pp. 454-472, 2020.

[19] D. Parkash and C. Deangeli, "Wellbore stability analysis in anisotropic shale formations," in SPE/PAPG Pakistan Section Annual Technical Symposium and Exhibition, Islamabad, Pakistan, 2019.

[20] T. Ma, N. Peng, Z. Zhu, Q. Zhang, C. Yang, and J. Zhao, "Brazilian tensile strength of anisotropic rocks: review and new insights," Energies, vol. 11, no. 2, p. 304, 2018.

[21] H. Lee, C. Chang, S. H. Ong, and I. Song, "Effect of anisotropic borehole wall failures when estimating in situ stresses: a case study in the Nankai accretionary wedge," Marine and Petroleum Geology, vol. 48, pp. 411-422, 2013.

[22] G. Chen, M. E. Chenevert, M. M. Sharma, and M. Yu, "A study of wellbore stability in shales including poroelastic, chemical, and thermal effects," Journal of Petroleum Science and Engineering, vol. 38, no. 3-4, pp. 167-176, 2003.

[23] A. Ghassemi, Q. Tao, and A. Diek, "Influence of coupled chemo-poro-thermoelastic processes on pore pressure and stress distributions around a wellbore in swelling shale," Journal of Petroleum Science and Engineering, vol. 67, no. 1-2, pp. 57-64, 2009.

[24] M. Gomar, I. Goodarznia, and S. R. Shadizadeh, "A transient fully coupled thermo-poroelastic finite element analysis of wellbore stability," Arabian Journal of Geosciences, vol. 8, no. 6, pp. 3855-3865, 2015.

[25] W. Liu and X. Zhu, "A coupled thermo-poroelastic analysis of wellbore stability for formations with anisotropic strengths," Arabian Journal of Geosciences, vol. 11, no. 18, p. 537, 2018.

[26] Q. Wang, Y. Zhou, G. Wang, H. Jiang, and Y. Liu, "A fluidsolid-chemistry coupling model for shale wellbore stability," Petroleum Exploration and Development, vol. 39, no. 4, pp. 508-513, 2012. 
[27] C. Liang, M. Chen, Y. Jin, and Y. Lu, "Wellbore stability model for shale gas reservoir considering the coupling of multiweakness planes and porous flow," Journal of Natural Gas Science and Engineering, vol. 21, pp. 364-378, 2014.

[28] S. Jia, Z. Xiao, B. Wu, C. Wen, and L. Jia, "Modelling of timedependent wellbore collapse in hard brittle shale formation under underbalanced drilling condition," Geofluids, vol. 2019, 21 pages, 2019.

[29] V. Dokhani, M. Yu, and B. Bloys, "A wellbore stability model for shale formations: accounting for strength anisotropy and fluid induced instability," Journal of Natural Gas Science and Engineering, vol. 32, pp. 174-184, 2016.

[30] R. Zhang, G. Li, and S. Tian, "Stress distribution and its influencing factors of bottom-hole rock in underbalanced drilling," Journal of Central South University, vol. 25, no. 7, pp. 1766-1773, 2018.

[31] S. He, W. Wang, H. Shen, M. Tang, H. Liang, and J.'. Lu, "Factors influencing wellbore stability during underbalanced drilling of horizontal wells - when fluid seepage is considered," Journal of Natural Gas Science and Engineering, vol. 23, pp. 80-89, 2015.

[32] S. He, W. Wang, M. Tang, B. Hu, and W. Xue, "Effects of fluid seepage on wellbore stability of horizontal wells drilled underbalanced," Journal of Natural Gas Science and Engineering, vol. 21, pp. 338-347, 2014.

[33] H. Lee, S. H. Ong, M. Azeemuddin, and H. Goodman, “A wellbore stability model for formations with anisotropic rock strengths," Journal of Petroleum Science and Engineering, vol. 96, pp. 109-119, 2012.

[34] X. Fan, M. Zhang, Q. Zhang, P. Zhao, B. Yao, and D. Lv, "Wellbore stability and failure regions analysis of shale formation accounting for weak bedding planes in ordos basin," Journal of Natural Gas Science and Engineering, vol. 77, article 103258, 2020.

[35] P. Bautmans, E. Fjær, and P. Horsrud, "The effect of weakness patches on wellbore stability in anisotropic media," International Journal of Rock Mechanics and Mining Sciences, vol. 104, pp. 165-173, 2018.

[36] J. Gao, J. Deng, K. Lan, Y. Feng, W. Zhang, and H. Wang, "Porothermoelastic effect on wellbore stability in transversely isotropic medium subjected to local thermal non-equilibrium," International Journal of Rock Mechanics and Mining Sciences, vol. 96, pp. 66-84, 2017.

[37] M. D. Zoback, Reservoir geomechanics, Cambridge University Press, 2010.

[38] F. K. Mody and A. H. Hale, "Borehole-stability model to couple the mechanics and chemistry of drilling-fluid/shale interactions," Journal of Petroleum Technology, vol. 45, no. 11, pp. 1093-1101, 1993.

[39] M. Meng, P. Chen, and R. Ren, "Statistic evaluation of failure criteria in wellbore stability with temperature effects," Fuel, vol. 252, pp. 730-752, 2019. 